\title{
Efficacy and safety of tocilizumab in european children with systemic onset juvenile idiopathic arthritis
}

\author{
O Nemiche ${ }^{\text {** }}$, R Dagner ${ }^{1}$, P Quartier ${ }^{1}$, R Cimaz ${ }^{2}$, O Richer ${ }^{3}$, P Pillet ${ }^{3}$, M Hofer $^{4}$ \\ From 18th Pediatric Rheumatology European Society (PReS) Congress \\ Bruges, Belgium. 14-18 September 2011
}

\section{Background}

The anti- IL-6 Receptor monoclonal antibody Tocilizumab (TCZ) has demonstrated its efficacy in Japanese children with systemic onset juvenile idiopathic arthritis (SJIA).

\section{Aim}

To evaluate the efficacy and safety of TCZ in European patients with active SJIA outside a clinical trial (off-label use).

\section{Patients and methods}

Retrospective review of the files of the patients treated by TCZ in two French, one Swiss and one Italian center. Response to treatment was defined as control of the fever and systemic features for at least 7 days, Improvement of the pediatric ACR score and normalization of erythrocyte sedimentation rate (ESR) and C-reactive protein (CRP) were also considered.

\section{Results}

18 patients aged 4-15 years were included. The median disease duration at treatment onset was 4.7 years (0.48.8). The median dose of prednisone at TCZ onset was $0.63 \mathrm{mg} / \mathrm{kg} / \mathrm{d}$. Four patients were also on MTX. Fourteen patients had previously failed to respond one or several biologics, including anti-TNF alpha in 10 cases, anakinra in 14 and canakinumab, in 4 . All patients but 4 had active systemic and polyarticular features at TCZ onset. The doses of TCZ ranged between 6 and $12 \mathrm{mg} / \mathrm{kg}$ every other week at treatment onset. The mean followup on TCZ was 18.2 months (range0.5-48). 90\% improvement of the pediatric ACR score was achieved by 9 patients after 3 months. The dose of steroids was tapered in most cases (11/14) within 3 months, and five patients could discontinue steroid treatment after 12 months. TCZ treatment was withdrawn in 5 children for adverse events: anaphylactic reaction in 3 cases, skin vasculitis in 2 other cases.

\section{Conclusion}

In this study TCZ treatment was effective in most patients with SJIA who previously failed one or several biologics. Adverse events require particular attention since almost one third of patients had to discontinue treatment.

\begin{abstract}
Author details
${ }^{1}$ Department of Immuno-Hémato-Rhumatology, Necker Enfants Malades Hospital, Paris France. ${ }^{2}$ Service of Pediatric Rheumatology, Florence Italy. ${ }^{3}$ Service of Pediatric Rheumatology, CHU Bordeaux, France. ${ }^{4}$ Service of Pediatric Rheumatology, CHU, Vaudois, Lausanne, Geneva, Swiss.
\end{abstract}

Published: 14 September 2011

doi:10.1186/1546-0096-9-S1-P135

Cite this article as: Nemiche et al:: Efficacy and safety of tocilizumab in european children with systemic onset juvenile idiopathic arthritis. Pediatric Rheumatology 2011 9(Suppl 1):P135. 